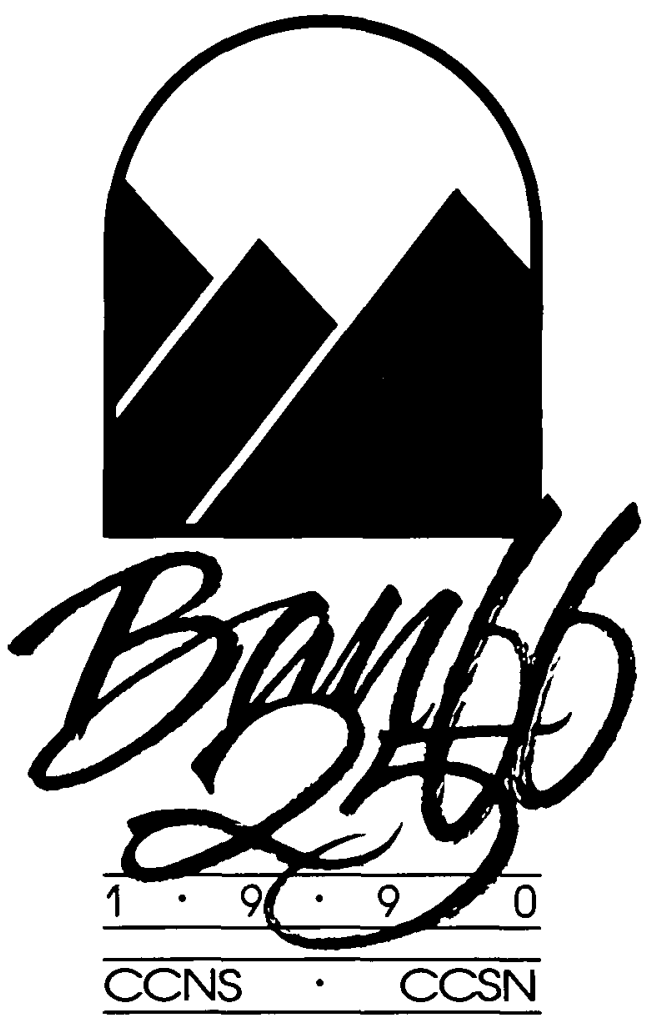

\title{
ADVERTISER'S INDEX
}

Abbott Laboratories Limited

Epival - viii, ix, xxvi

Ciba/Geigy

Lioresal - ii, xxiv

Tegretol - obc, xiii, xxiii

Cordis Canada - vii

Dantec Electronics Ltd.

Concerto - $x i$

Counterpoint - $x x$

Neuroscope - xv

Dupont

Symmetrel - xvii, xxv

Geigy

Tegretol - obc, xiii, xxiii

Genderme

Zostrix - $x, x x v$

Hoffman La Roche

Prolopa - xvi, xxiv

Nicolet Instruments - xii, xix

Nihon Kohden - vi

Parke Davis Canada Inc.

Dilantin - ibc, xviii

Pudenz - Schulte Medical - iv

Sandoz Canada Inc.

Parlodel - ifc, i, xxii

STT Medical - xiv

Classified Ads - xxvii, xxviii

\section{FELLOWSHIP POSITIONS}

\section{University of Miami School of Medicine}

\section{NEUROTRAUMATOLOGY}

A one year Neurotraumatology fellowship is offered for applicants who have completed or are in the final year of their neurosurgical training.

\section{NEUROSURGICAL CRITICAL CARE}

A one year fellowship in Neurological Critical Care is offered for applicants who have completed their training in neurosurgery, neurology, or anesthesiology.

The University of Miami/Jackson Memorial Medical Center has one of the nation's largest Neurotrauma Services, as well as a 12 bed, state-of-the-art Neurosurgical Intensive Care Unit.

Opportunity for either clinical or laboratory research is also provided. Applicants must be eligible for Florida licensure. Stipend and benefits provided.

Interested applicants should contact:

\author{
Jonathan Greenberg, M.D., J.D. \\ Neurotrauma Service - JMH \\ Dept. of Neurological Surgery \\ University of Miami \\ School of Medicine \\ 1501 NW 9th Avenue \\ Miami, Florida 33136 \\ (305) $547-6946$ \\ (305) 674-2393
}

Philip A. Villanueva, M.D.

Associate Director - NSICU

Dept. of Neurological Surgery

University of Miami

School of Medicine

1501 NW 9th Avenue

Miami, Florida 33136

(305) 547-6946

(305) 547-7163 